\title{
AN EXTENSION OF THE IDENTIFICATION ALGORITHM FOR FEEDBACK ACTIVE CONTROL OF INCOMPLETE MEASURED SYSTEMS
}

\author{
La Duc Viet, Nguyen Dong Anh \\ Institute of Mechanics
}

\begin{abstract}
In a previous paper [1], the identification algorithm is presented for feedback active controlled systems. However, this method can only be applied to complete measured systems. The aim of this paper is to present a combination of the identification algorithm and the modal superposition method to control the incomplete measured systems. The system response is expanded by modal eigenfunction technique. The external excitation acting on some first modes is identified with a time delay and with a small error depending on the sensor locations. Then the control forces will be generated to balance the identified excitations. $\Lambda$ numerical simulation is applied to an eight story building subjected to base acceleration.
\end{abstract}

\section{INTRODUCTION}

The active control method can be applied to many problems such as robot control, ship autopilot, airplane autopilot, vibration control of vehicles or structures ... Fig. 1 provides a schematic diagram of an active control system.

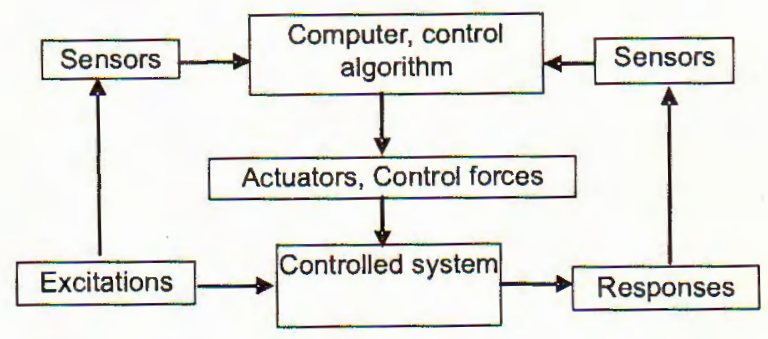

Fig. 1. Diagram of a structural control system

It consists of 3 main parts: sensors to measure either external excitations or system responses or both; computer controller to process the measured information and to compute necessary control force based on a given control algorithm; actuators to produce the required forces. When only the responses can be measured, the method is called feedback active control. In recent years, the active control method has been widely used to reduce the excessive vibrations of civil structures due to environmental disturbances ([2]). One of the basic tasks of active structural control problem is to determine a control strategy that 
uses the measured structural responses to calculate an appropriate control signal to send to the actuator. Many control strategies have been proposed, such as LQR/LQG control [3], $\mathrm{H}_{2} / \mathrm{H}_{\infty}$ control [4,5], sliding mode control [6], saturation control [7], reliability-based control [8], fuzzy control [9], neural control [10]... We also proposed two control algorithms for structural control. The first applies to structures, in which some components of excitation can be known [11] and the second applies to structures, in which the control forces are bounded [12]. In fact, it is usually that one is unable to measure the external excitation while the structural response can often be measured. The identification algorithm presented in [1] is a method, which identifies the external excitation from the structural response measured. Although this version of identification algorithm can be applied even for the nonlinear structures, it requires knowledge of the entire displacement vector of the structure, which is not possible for large structures. Thus, the aim of this paper is to combine the identification algorithm and the modal superposition method for the linear structures with incomplete measurement, i.e only some components of response vector can be measured.

\section{PROBLEM FORMULATION}

Consider a multi-degree-of-freedom system described by the second order linear differential equation

$$
M \ddot{x}(t)+D \dot{x}(t)+K x(t)=u(t)+f(t), \quad x(0)=x_{0},
$$

where $x(t)$ is the $n$-dimensional displacement vector , $f(t)$ is the $n$-dimensional external force vector, $u(t)$ is the $n$-dimensional control vector, three $n \times n$ matrices $M, D$ and $K$ are mass, damping and stiffness matrices, respectively. Let $y(t)$ be the $p$-dimensional measurement (output) vector $(p \leq n)$ with:

$$
y(t)=C x(t)
$$

where $C$ is a $p \times n$ measurement matrix. The control force vector $u(t)$ is selected as a function of the measurement vector $y(t)$. The control problem is to find the active control force $u(t)$ necessary to reduce the norm state vector. It is seen obviously that the best control law is that

$$
u(t)=-f(t)
$$

Indeed with control law (3), the external excitation is totally eliminated. However, it is usually that one is unable to measure the external excitation, so the control law (3) cannot be realized practise. The idea involved in the control law (3) may be used in a modified way, in, which the history of the external excitation can be identified with a time delay by a so called identification process. The process identifying the entire external excitation is presented in [1] and here and after is called the original identification algorithm. The original identification algorithm requires the knowledge of the entire state vector to identify the entire excitation. However, when only the measurement vector in (2) can be measured, the excitation can not be identified all. In this paper, by using modal superposition method, the identification algorithm will be extended to identify some most important excitations based on the measurement vector $y(t)$. The detail of this extension is presented in section 4. 


\section{IDENTIFICATION ALGORITHM}

The original identification algorithm developed in [1] is shortly presented here. Let $T$ be the time duration of the action of external excitation. Let all the components of the displacement vector $x(t)$ can be measured and all components of its first and second order derivatives can be calculated in a short time. The interval $[0, T]$ is divided into $n$ small equal intervals of the length $\Delta$ where $\Delta$ is a small positive number whose value depends on computation speed and accuracy of computer. Thus one has:

$$
T=q \Delta
$$

For any given function vector $m(t)$, the following notation is introduced:

$$
m^{(k)}(t)=\left\{\begin{array}{ll}
m(t) & (k-1) \Delta \leq t \leq k \Delta \\
0 & \text { otherwise }
\end{array} \quad k=1,2, \ldots, q\right.
$$

In $T_{k}=[(k-1) \Delta \leq t \leq k \Delta]$, the system response is described by the following equation:

$$
M \ddot{x}^{(k)}(t)+D \dot{x}^{(k)}(t)+K x^{(k)}(t)=u^{(k)}(t)+f^{(k)}(t) .
$$

In this subinterval, we assume that the control force $u^{(k)}(t)$ can be known (by the control law (7) below), the displacement vector $x^{(k)}(t)$ is measured, the velocity and acceleration vectors are calculated. Thus, the external disturbance $f^{(k)}(t)$ can be calculated as

$$
f^{(k)}(t)=M \ddot{x}^{(k)}(t)+D \dot{x}^{(k)}(t)+K x^{(k)}(t)-u^{(k)}(t) .
$$

So, at the end of the subinterval $T_{k}$, one can know all about $f(t)$ in this subinterval. Because the subinterval $T_{k}$ ended, this information can be used only in the next subinterval $T_{k+1}$ to calculate $u^{(k+1)}(t)$, This means that the information about $f(t)$ has a time delay $\Delta$. Using the information of the delayed external excitation $f(t)$, the control algorithm is proposed as:

$$
\left\{\begin{aligned}
& u^{(1)}(t)=0 \\
& u^{(k)}(t)=-f^{(k-1)}(t-\Delta) \\
&=-\left[M \ddot{x}^{(k-1)}(t-\Delta)+D \dot{x}^{(k-1)}(t-\Delta)+K x^{(k-1)}(t-\Delta)-u^{(k-1)}(t-\Delta)\right] \\
& k=2,3 \ldots, q
\end{aligned}\right.
$$

As we see, the control law (7) is established in the inductive way. With control law (7), the delayed external excitation $f(t-\Delta)$ is totally eliminated. Substituting (7) into (1), the differential equation of the controlled system has form:

$$
M \ddot{x}(t)+D \dot{x}(t)+K x(t)=-f(t-\Delta)+f(t)
$$

One has:

$$
\|-f(t-\Delta)+f(t)\|=\Delta\|\dot{f}(\zeta)\|
$$

where $\zeta$ is a value between $t$ and $t-\Delta$. Therefore, it is easy to see that the norm of excitation is sufficiently small if the time delay $\Delta$ is small. However, as mentioned above, the disadvantage of the original identification algorithm is the requirement of the knowledge of entire displacement vector $x(t)$. 


\section{IDENTIFICATION ALGORITHM USING MODAL SUPERPOSITION METHOD}

Incomplete measurement leads to incomplete excitation identification. Two questions need to be addressed: which excitation is important and how to identify it? These questions are not easy to answer if the system is nonlinear. However, in case of the linear system modeled in (1), the answer can be found by well-known modal eigenfunction technique. The decoupled modal equations take the form:

$$
\ddot{z}_{i}(t)+2 \xi_{i} \omega_{i} \dot{z}_{i}(t)+\omega_{i}^{2} z_{i}(t)=\Phi_{i}^{T} u(t)+\Phi_{i}^{T} f(t), i=1, \ldots, n,
$$

where $\xi_{i}$ and $\omega_{i}(i=1, \ldots, n)$ are respectively the $i^{\text {th }}$ damping ratio and the $i^{\text {th }}$ natural frequency. $\Phi_{i}$ and $z_{i}(i=1, \ldots, n)$ are corresponding eigenvectors and modal coordinates. The measurement vector $y(t)$ is also rewritten in modal space:

$$
y=\sum_{i=1}^{n} C \Phi_{i} z_{i} .
$$

As one knows, the vibrational modes corresponding to large natural frequencies often contribute little to the response [13], so attention needs to be paid only to a few vibrational modes. Denote $z_{c}$ as the vector containing the first $p$ modal coordinates and $z_{r}$ as the vector containing the remaining $n-p$ modal coordinates. This means:

$$
z_{c}=\left[\begin{array}{llll}
z_{1} & z_{2} & \ldots & z_{p}
\end{array}\right]^{T} ; \quad z_{r}=\left[\begin{array}{llll}
z_{p+1} & z_{p+2} & \ldots & z_{n}
\end{array}\right]^{T}
$$

Then (8) and (9) are rewritten as

$$
\begin{gathered}
\ddot{z}_{c}(t)+2 \Psi_{c} \Omega_{c} \dot{z}_{c}(t)+\Omega_{c}^{2} z_{c}(t)=\Phi_{c}^{T} u(t)+\Phi_{c}^{T} f(t), \\
\ddot{z}_{r}(t)+2 \Psi_{r} \Omega_{r} \dot{z}_{r}(t)+\Omega_{r}^{2} z_{r}(t)=\Phi_{r}^{T} u(t)+\Phi_{r}^{T} f(t), \\
y=C_{c} z_{c}+C_{r} z_{r}
\end{gathered}
$$

where $\Psi_{c}, \Psi_{r}, \Omega_{c}$ and $\Omega_{r}$ are diagonal matrices are defined as:

$$
\begin{aligned}
\Psi_{c} & =\operatorname{diag}\left[\begin{array}{llll}
\xi_{1} & \xi_{2} & \ldots & \xi_{p}
\end{array}\right], \quad \Psi_{r}=\operatorname{diag}\left[\begin{array}{llll}
\xi_{p+1} & \xi_{p+2} & \ldots & \xi_{n}
\end{array}\right] \\
\Omega_{c} & =\operatorname{diag}\left[\begin{array}{lllll}
\omega_{1} & \omega_{2} & \ldots & \omega_{p}
\end{array}\right], \quad \Omega_{r}=\operatorname{diag}\left[\begin{array}{llll}
\omega_{p+1} & \omega_{p+2} & \ldots & \omega_{n}
\end{array}\right]
\end{aligned}
$$

and $\Phi_{c}, \Phi_{r}, C_{c}$ and $C_{r}$ are defined as:

$$
\begin{gathered}
\Phi_{c}=\left[\begin{array}{cccc}
\Phi_{1} & \Phi_{2} & \ldots & \Phi_{p}
\end{array}\right] ; \quad \Phi_{r}=\left[\begin{array}{llll}
\Phi_{p+1} & \Phi_{p+2} & \ldots & \Phi_{n}
\end{array}\right] \\
C_{c}=C \Phi_{c} ; \quad C_{r}=C \Phi_{r}
\end{gathered}
$$

Because attention needs to be paid only to the first $p$ modes, we need to identify and eliminate the excitation $\Phi_{c}^{T} f(t)$. The identification process here is implemented in the same manner as the process in section 3 . The interval $[0, T]$ is also divided into $n$ small equal intervals of the length. $\Delta$. Using the notation (4), in $T_{k}=[(k-1) \Delta \leq t \leq k \Delta]$, the equation (10) has form:

$$
\ddot{z}_{c}^{(k)}(t)+2 \Psi_{c} \Omega_{c} \dot{z}_{c}^{(k)}(t)+\Omega_{c}^{2} z_{c}^{(k)}(t)=\Phi_{c}^{T} u^{(k)}(t)+\Phi_{c}^{T} f^{(k)}(t)
$$


Using (12), we have

$$
\begin{aligned}
\Phi_{c}^{T} f^{(k)}(t)= & \ddot{z}_{c}^{(k)}(t)+2 \Psi_{c} \Omega_{c} \dot{z}_{c}^{(k)}(t)+\Omega_{c}^{2} z_{c}^{(k)}(t)-\Phi_{c}^{T} u^{(k)}(t) \\
= & C_{c}^{-1}\left(\ddot{y}^{(k)}(t)-C_{r} \ddot{z}_{r}^{(k)}(t)\right)+2 \Psi_{c} \Omega_{c} C_{c}^{-1}\left(\dot{y}^{(k)}(t)-C_{r} \dot{z}_{r}^{(k)}(t)\right)+ \\
& +\Omega_{c}^{2} C_{c}^{-1}\left(y^{(k)}(t)-C_{r} z_{r}^{(k)}(t)\right)-\Phi_{c}^{T} u^{(k)}(t) .
\end{aligned}
$$

Then

$$
\Phi_{c}^{T} f^{(k)}(t)+E^{(k)}(t)=C_{c}^{-1} \ddot{y}^{(k)}(t)+2 \Psi_{c} \Omega_{c} C_{c}^{-1} \dot{y}^{(k)}(t)+\Omega_{c}^{2} C_{c}^{-1} y^{(k)}(t)-\Phi_{c}^{T} u^{(k)}(t),
$$

where

$$
E^{(k)}(t)=C_{c}^{-1} C_{r} \ddot{z}_{r}^{(k)}(t)+2 \Psi_{c} \Omega_{c} C_{c}^{-1} C_{r} \dot{z}_{r}^{(k)}(t)+\Omega_{c}^{2} C_{c}^{-1} C_{r} z_{r}^{(k)}(t) .
$$

In the subinterval $T_{k}$, we assume that the control force $u_{c}^{(k)}(t)$ can be known (by the control law (15) below), the measurement vector $y^{(k)}(t)$ is known, and the first and second derivatives are calculated. The error term $E^{(k)}(t)$ introduced through the truncation process is still unknown. Thus, from (13), we can not know the exact excitation $\Phi_{c}^{T} f(t)$, but only an estimate of $\Phi_{c}^{T} f(t)$ to with an error $E(t)$. To attenuate this error term, the sensors should be located to obtain a significant contribution of the information of $x_{c}$. This means a large norm of $C_{c}$ in comparison with the norm of $C_{r}$. Because the subinterval $T_{k}$ ended, the information known can be used only in the next subinterval $T_{k+1}$ to calculate $u^{(k+1)}(t)$. Using the delayed information, the control force $\Phi_{c}^{T} u(t)$ acting on the significant modes $z_{c}$ is proposed as:

$$
\left\{\begin{aligned}
\Phi_{c}^{T} u^{(1)}(t)= & 0 \\
\Phi_{c}^{T} u^{(k)}(t)= & -\left\{\Phi_{c}^{T} f^{(k-1)}(t-\Delta)+E^{(k-1)}(t-\Delta)\right\} \\
= & -\left[C_{c}^{-1} \ddot{y}^{(k-1)}(t-\Delta)+2 \Psi_{c} \Omega_{c} C_{c}^{-1} \dot{y}^{(k-1)}(t-\Delta)\right. \\
& \left.+\Omega_{c}^{2} C_{c}^{-1} y^{(k-1)}(t-\Delta)-\Phi_{c}^{T} u^{(k-1)}(t-\Delta)\right] ; \quad k>1
\end{aligned}\right.
$$

To ensure the stability of the controlled system, the control force $u(t)$ must be chosen to make the error $E(t)$ in (14) independen the control process. This means that the control force $\Phi_{r}^{T} u(t)$ acting on the insignificant vibrational mode $z_{r}$ must be set to zero for the entire time duration

$$
\Phi_{r}^{T} u(t)=0 .
$$

At last, we determine the physical control force $u(t)$ by transformation from modal space to state space:

$$
u=\left[\begin{array}{c}
\Phi_{c}^{T} \\
\Phi_{r}^{T}
\end{array}\right]^{-1}\left[\begin{array}{c}
\Phi_{c}^{T} \\
\Phi_{r}^{T}
\end{array}\right] u=\left[\begin{array}{c}
\Phi_{c}^{T} \\
\Phi_{r}^{T}
\end{array}\right]^{-1}\left[\begin{array}{l}
\Phi_{c}^{T} u \\
0
\end{array}\right]
$$

where $\Phi_{c}^{T} u(t)$ is calculated from (15). The control law using the combination of the identification algorithm and the modal superposition method is described by (15) and (17). Substituting (15) and (16) into (10) and (11), the modal differential equations of the controlled system take the form:

$$
\begin{gathered}
\ddot{z}_{c}(t)+2 \Psi_{c} \Omega_{c} \dot{z}_{c}(t)+\Omega_{c}^{2} z_{c}(t)=-\Phi_{c}^{T} f(t-\Delta)-\Phi_{c}^{T} E(t-\Delta)+\Phi_{c}^{T} f(t) \\
\ddot{z}_{r}(t)+2 \Psi_{r} \Omega_{r} \dot{z}_{r}(t)+\Omega_{r}^{2} z_{r}(t)=\Phi_{r}^{T} f(t)
\end{gathered}
$$


One has:

$$
\left\|-\Phi_{c}^{T} f(t-\Delta)-\Phi_{c}^{T} E(t-\Delta)+\Phi_{c}^{T} f(t)\right\| \leq \Delta\|\dot{f}(\zeta)\|+\left\|\Phi_{c}^{T} E(t)\right\| \cdot
$$

It can be seen that the norm of the excitation acting on the significant modes $z_{c}$ is small if the time delay and the error term $E$ are small. Because the error term $E$ defined in (14) depends only on the insignicant modes $\mathrm{z}_{r}$, we assume this error is sufficiently small. However, the effect of this term on the control process should be the subject for further investigations.

\section{NUMERICAL SIMULATION}

Consider an eight-story building subject to base acceleration as shown in Fig. 2.
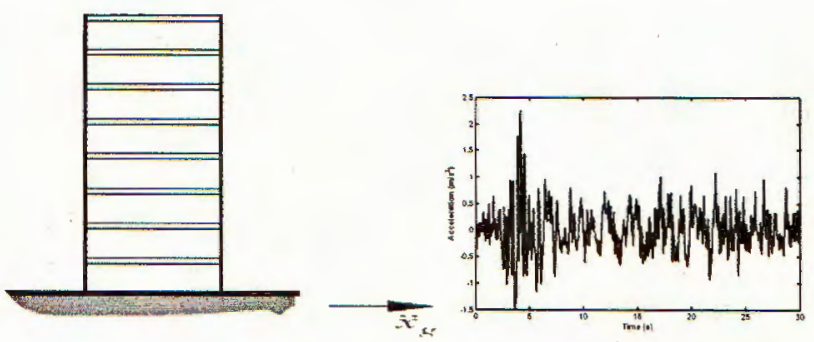

Fig. 2. Model of an eight story building subjected to base acceleration

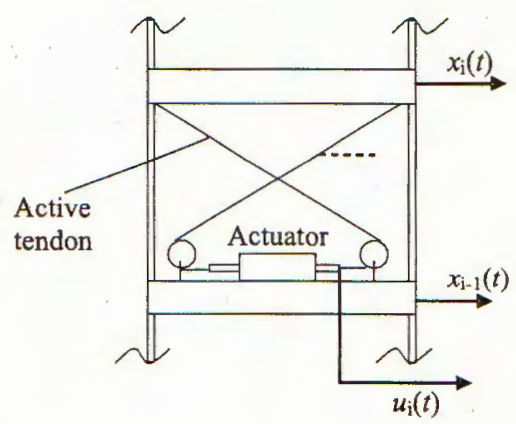

Fig. 3. Active tendon system between two floors

The history of base acceleration is taken from the N-S component recorded at Hachinohe City during the Tokachioki earthquake of May 16, 1968. The absolute peak acceleration of the earthquake record is $2.25 \mathrm{~m} / \mathrm{s}^{2}$. The characteristics of the building are the same for each story: floor mass $m$, elastic stiffness $k$ and internal damping coefficient $d$. The control force is applied to the structure through a set of tendons connected to an actuator placed between each two floors. The active tendon generally consists of a set of prestressed tendons whose tensions are controlled by electrohydraulic servomechanism [13]. Fig. 3 shows an active tendon mechanism between two floors:

It is not difficult to derive the structural motion equation as:

$$
M \ddot{x}(t)+D \dot{x}(t)+K x(t)=u(t)+f(t)
$$


where the mass, damping and stiffness matrices have form

$$
M=\left[\begin{array}{ccccc}
8 & 7 & 6 & \ldots & 1 \\
7 & 7 & 6 & \ldots & 1 \\
6 & 6 & 6 & \ldots & 1 \\
\vdots & \vdots & \vdots & \ddots & 1 \\
1 & 1 & 1 & 1 & 1
\end{array}\right] m ; \quad D=\operatorname{diag}(d, d, \ldots, d) ; \quad K=\operatorname{diag}(k, k, \ldots, k)
$$

The displacement vector $x$, the control vector $u$ and the excitation vector $f$ have the form:

$$
\begin{aligned}
x & =\left[\begin{array}{lllll}
x_{1} & x_{2}-x_{1} & x_{3}-x_{2} & \ldots & x_{8}-x_{7}
\end{array}\right]^{T} \\
u & =-2 k_{c} \cos \alpha\left[\begin{array}{llllll}
u_{1} & u_{2} & u_{3} & \ldots & u_{8}
\end{array}\right]^{T} \\
f & =-\left[\begin{array}{lllll}
8 & 7 & 6 & \ldots & 1
\end{array}\right]^{T} m \ddot{x}_{g}
\end{aligned}
$$

in which, $x_{i}(i=1, . .8)$ are the relative displacement of the $i^{\text {th }}$ floor with respect to the foundation, $u_{i}(i=1, . .8)$ are the corresponding actuator displacements, $k_{c}, \alpha$ and $\ddot{x}_{g}$ denote, respectively the tendon stiffness, the tendon angle and the base acceleration. Let the parameters take values as in [14]: $m=345.6$ metric tons, elastic stiffness $k=3.404 \times 10^{5}$ $\mathrm{kN} / \mathrm{m}$, internal damping coefficient $d=2937$ metric tons $/ \mathrm{sec}, k_{c}=10^{5} \mathrm{kN} / \mathrm{m}$ and $\alpha=36^{\circ}$ .The natural frequencies of this building are $5.79,17.18,27.98,37.83,46.39,53.37$ and $61.70 \mathrm{rad} / \mathrm{s}$. The damping ratios of some first modes are $2.4 \%, 7.4 \%, 12 \%, 16.3 \%$. We assume only one sensor measures the relative displacement of a certain floor with respect to the below floor. If the sensor is located on the $i$ th floor, the measurement matrix $C$ in (2) has the form:

$$
C=\left[\begin{array}{llllll}
0 & 0 & \ldots & 1 & \ldots & 0
\end{array}\right]
$$

The displacement vector of the structure has 8 components, of which only the first mode is controlled by the identification algorithm. The numerical simulation is taken with different time delays and with different sensor locations. As we see from (14), the magnitude of the error term depends mainly on the magnitude of the matrix $C_{c}^{-1} C_{r}$. Table 1 shows the norms of $C_{c}^{-1} C_{r}$ for different sensor locations

Table 1. The norms of $C_{c}^{-1} C_{r}$ in different cases

\begin{tabular}{|c|c|c|c|c|c|c|c|c|}
\hline Sensor Floor Location & 1 & 2 & 3 & 4 & 5 & 6 & 7 & 8 \\
\hline Norm of $C_{c}^{-1} C_{r}$ & 11.2 & 16.4 & 17.6 & 19.8 & 23.4 & 30.0 & 43.7 & 86.0 \\
\hline
\end{tabular}

It can be seen that the error produced through the truncation process in (14) might be larger if the sensor location is higher. To see this more clearly, we plot the history of the error term $E(t)$ in (14). The histories of $E(t)$ are plotted in Fig. 4 for each case of the sensor location. It can be seen that, the $3^{\text {rd }}$ floor is the best sensor location and the $8^{\text {th }}$ floor is the worst sensor location. However, more investigate need to be done in the future to find the method seeking the optimal sensor locations.

The time delay is taken as $1 / 500$ and $1 / 800$ of the total duration time. The displacements of the top floor relative to foundation and actuator displacements are compared in Table 2 


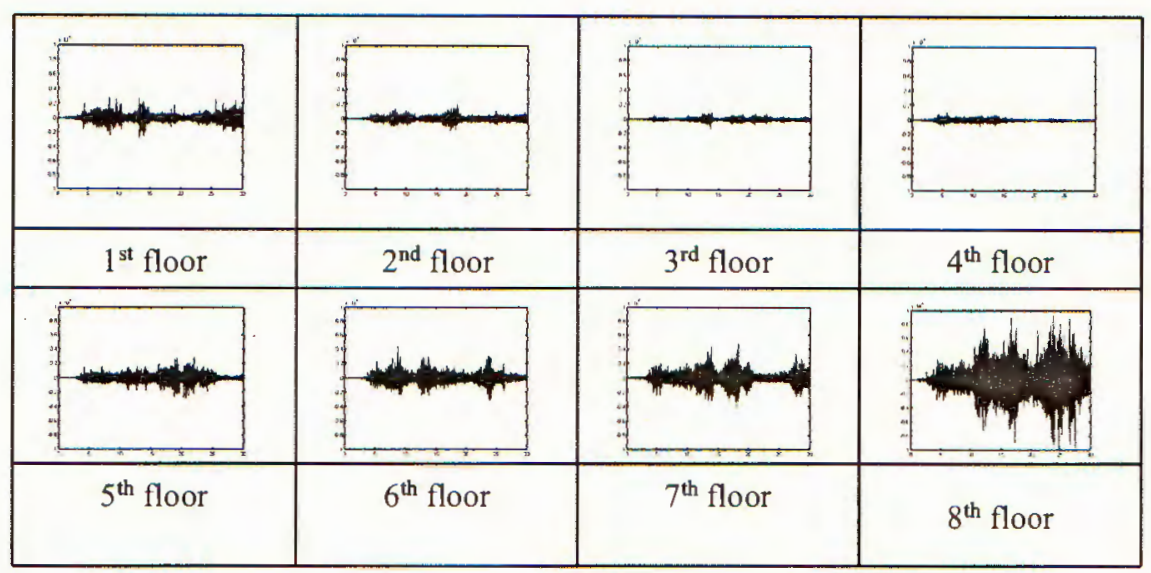

Fig. 4. Error term $E(t)$ histories for 8 choices of sensor location

Table 2. The maxima displacements of the top floor in the numerical simulation

\begin{tabular}{|c|c|c|c|}
\hline Sensor location & $\begin{array}{c}\text { Controlled, } \\
\text { Time delay } \\
\Delta=0.2 \% \mathrm{~T}(\mathrm{~cm})\end{array}$ & $\begin{array}{c}\text { Controlled, } \\
\text { Time delay } \\
\mathrm{r} \Delta=0.125 \% \mathrm{~T}(\mathrm{~cm})\end{array}$ & $\begin{array}{c}\text { Uncontrolled } \\
(\mathrm{cm})\end{array}$ \\
\hline $1^{\text {st }}$ floor & 6.76 & 5.13 \\
\hline $2^{\text {nd }}$ floor & 5.61 & 4.34 \\
\hline $3^{\text {rd }}$ floor & 4.10 & 2.85 & \multirow{2}{*}{13.4} \\
\hline $4^{\text {th }}$ floor & 4.79 & 2.61 & \\
\hline $5^{\text {th }}$ floor & 4.90 & 3.61 & \\
\hline $6^{\text {th }}$ floor & 7.26 & 5.70 \\
\hline $7^{\text {th }}$ floor & 8.31 & 7.53 \\
\hline $8^{\text {th }}$ floor & 10.23 & 8.89 \\
\hline
\end{tabular}

The histories of the top floor displacement in two cases of sensor location: $3^{\text {rd }}$ floor (the best case) and $8^{\text {th }}$ floor (the worst case) are shown in Fig. 5 and 6 . In the figures, bold limes trace the controlled response, and light dotled lines the uncontrolled response thin and dotted lines are uncontrolled responses

As we see, the effect of identification algorithm depends on the error term $E(t)$ and the time delay $\Delta$. The more small $E(t)$ and $\Delta$ are, the better identification control algorithm is.

\section{CONCLUSION}

The aim of this paper is to extend the identification algorithm for feedback active control of incomplete measured systems. The system is expanded to the modal space. A limited number of sensors is used to measure some components of the displacement vector. Using this incomplete information, an algorithm is presented to identify the external excitation acting on some first modes. The excitation is identified with a time delay and a small error term. The magnitude of the error term depends on sensor numbers and locations. To illustrate the algorithm, the numerical simulation is applied to an eight story 


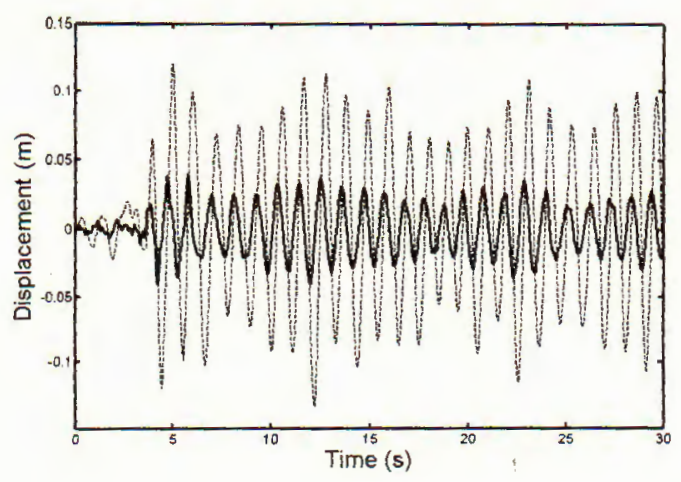

(a)

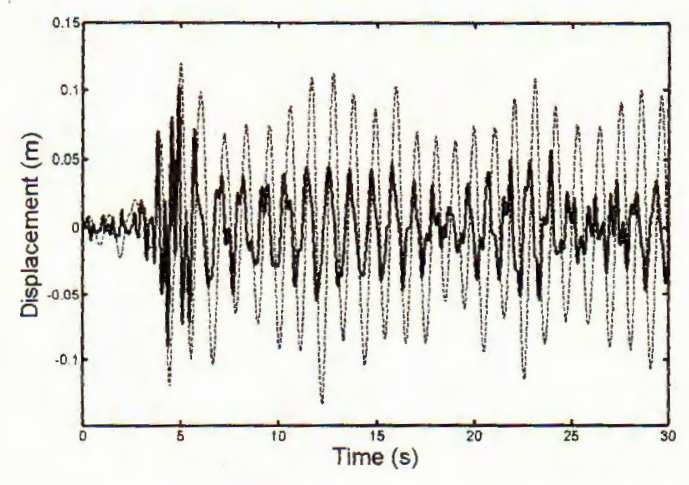

(b)

Fig. 5. The histories of the top floor displacement, $\Delta=0.2 \% \mathrm{~T}$, sensor is located on the 3rd floor (a) and on the 8th floor (b)

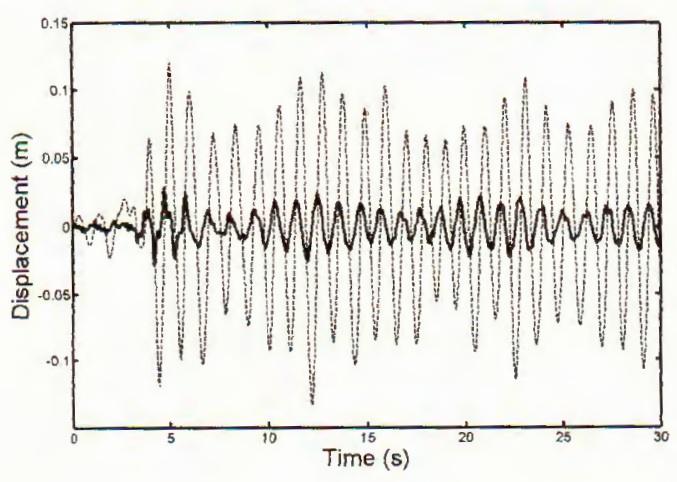

(a)

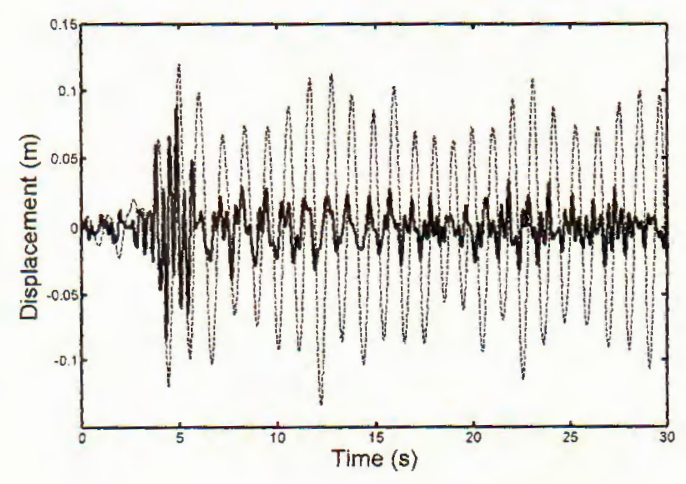

(b)

Fig. 6. The histories of the top floor displacement, $\Delta=0.125 \% \mathrm{~T}$, sensor is located on the 3rd floor (a) and on the 8th floor (b)

building subjected to base acceleration. The effects of the time delay and sensor location are considered.

\section{REFERENCES}

1. N. D. Anh, An identification algorithm for feedback active control, Proceedings of the $3^{\text {Td }}$ International Workshop on Structural Control, (2000), 27-38.

2. B. F. Spencer, Jr and Michael K. Sain, Controlling Buildings: A New Frontier in Feedback, Special Issue of the IEEE Control Systems Magazine on Emerging Technology, 17 (1997) 19-35.

3. Kwakernaak H and Sivan R, Linear Optimal Control Systems, 1972, Wiley, NewYork.

4. J. Suhardjo, B. F. Spencer, Jr. and A. Kareem, Frequency Domain Optimal Control of Wind Excited Buildings, J. Engrg. Mech., ASCE 118 (1992) 2463-2481.

5. F. Jabbari, W. E. Schmitendorf and J.N. Yang, H-infinity Control for Seismic-Excited Buildings with Acceleration Feedback, J. Engrg.Mech., ASCE 121 (1995) 994-1002. 
6. J. N. Yang, J. C. Wu and A. K. Agrawal, Sliding Mode Control for Seismically Excited Linear Structures, J. Engrg. Mech., ASCE 121 (1995) 1386-1390.

7. A. K. Agrawal, J. N. Yang, W. E. Schmitendorf and F. Jabbari, Stability of Actively Controlled Structures with Actuator Saturation, J.Struct. Engrg., ASCE 123 (1997) 505-512.

8. B. F. Spencer, Jr., M.K. Sain, J.C. Kantor and C. Montemagno, Probabilistic Stability Measures for Controlled Structures Subject to Real Parameter Uncertainties, Smart Mat. and Struct., 1 (1992) 294-305.

9. F. Casciati, L. Faravelli and T. Yao, Control of Nonlinear Structures Using the Fuzzy Control Approach, Nonlinear Dynamics, 11 (1996) 171-187

10. P. Venini and Y.K. Wen, Hybrid Vibration Control of MDOF Hysteretic Structures with Neural Networks, Proc. 1st World Conf. on Stmuct. Control, 1994, pp. TA3:53-62.

11. N.D.Anh, L.D.Viet, On the local optimal control counterforces in active controlled structures, Proceedings of the International Conference on Advances in Building Technology 2 (2002) 937-944

12. Nguyen Dong Anh, La Duc Viet, A version of identification control algorithm for feedback active controlled nonlinear systems, Proceedings of The 8th International Conference on Mechatronics Technology (2004), 239-243

13. T. T. Soong, Active Structural Control: Theory and Practice, 1989, John Willey \& Son, Inc, NewYork.

14. J. N. Yang, Control of tall buildings under earthquake excitation, Journal of the Engineering Mechanics Division, ASCE, 108 (EM5), 1982, 833-849.

Received April 23, 2007

\section{MỞ RộNG THUẬT TOÁN NHẬN DẠNG CHO BÀI TOÁN DIỀU KHIỂN TÍCH CỰC PHẢN HỒI CƯA CÁC HỆ BỊ DO HẠN CHẾ}

Trong bài báo đã được công bố [1], thuật toán nhận dạng đã được trình bày cho các hệ được điều khiển tích cực phản hồi. Tuy nhiên, phương pháp này mới chỉ áp dụng cho các hệ được đo hoàn toàn. Mục đích cùa bài báo là trình bày một sự kết hợp giữa thuật toán nhân dang và phương pháp chồng chất các dạng riêng đề điều khiển các hệ bị đo hạn chế. Đáp ứng của hệ được tách bằng kỹ thuật dạng riêng. Kích động ngoài tác động vào một số dạng riêng đầu tiên được nhận dạng với một thời gian trễ và một thành phần sai số phụ thuộc vào vị trí đặt đầu đo. Sau đó lực điều khiển được sinh ra để cân bằng với kích động ngoài đã được nhận dạng. Mô phóng số được thực hiện cho mô hình nhà 8 tầng chịu tải gia tốc nền 